\title{
On Optimizing Steering Performance of Multi-axle Vehicle Based on Driving Force Control
}

\author{
Zhicheng $\mathrm{Wu}^{1}$, Cong Chen \\ ${ }^{1}$ Beijing Institute of Technology, School of Mechanical Engineering, Beijing, China
}

\begin{abstract}
The steering performance of multi-axle vehicle with independent driving system is affected by the distribution of the wheel driving force. A nonlinear vehicle dynamics model including magic formula tire model for describing 11 DoF four-axle vehicle with dual-front-axle-steering (DFAS) system was presented. The influence of different driving force distribution scheme on the steering performance of the vehicle was analyzed. A control strategy for improving the steady response and transient response of the vehicle steering is proposed. The results show: For the steady response, setting different drive force for internal and external wheels according to the actual steering characteristics of the vehicle can effectively improve its steering characteristics; For the transient response, adopting the zero sideslip angle control strategy and using the PID control algorithm to control the driving force of the outside wheel of tear-two-axle, under angle step input, the vehicle sideslip angle can quickly stabilize to 0 and yaw rate also significantly decreases.
\end{abstract}

\section{Introduction}

With the development of industrial, the application of multi-axle vehicle more widely. Multi-axle vehicles have large weight and moment of inertia, the handling stability of these vehicles is poor when steering[1]. So there is a strong practical significance to improve the steering performance of multi-axle vehicles.

At present, the worldwide researchers mainly focus on the control and distribution of steering angle of multi-axle vehicles. Hakima A found a relationship of steering angle between front and rear wheel to ensure the stability of the vehicle in different speed and different steering angle by simulation analysis, and designed a fuzzy controller to improve the steering stability of the vehicle[2]. Hamzah $\mathrm{N}$ used 2-DOF vehicle model as a reference to design a sliding mode controller, adjusted the four wheel steering angles in real time to stabilize the vehicle, and proved the stability of the controller[3]. Williams D E derived the degree of understeer and equivalent wheelbase expression of multi-axis vehicle, where the axle can contain any number of steering axes, resulting in more general conclusions.[4] Tabbache B taked a vehicle which driven by two electric wheels as research object, and proposed a method based on adaptive control, which used direct torque control and adaptive flux-speed observer to control the each wheel of the vehicle, to improve the reliability of the vehicle.[5]

This paper researches to optimize the steering performance of four-axle vehicle with DFAS system by reasonably distributing the driving force of different wheels. In this paper, an 11-DOF nonlinear vehicle dynamics model with wheel motion is established using the magic formula tire model. In this paper, the control strategy was researched using Matlab/SIMULINK. Based on the zero centroid side angle principle, the PID control algorithm is used to distribute the wheel driving force reasonably to optimize the steering performance of independent driving multi-axle vehicle.

\section{Nonlinear Vehicle Dynamics Model}

This paper establishes a nonlinear vehicle model with 11-DOF, which is longitudinal, lateral, yaw motion and eight-wheel rotary motion. The model can simulate the linear drive and steering drive and other complex conditions[6], the vehicle dynamics model is shown in Figure.1.

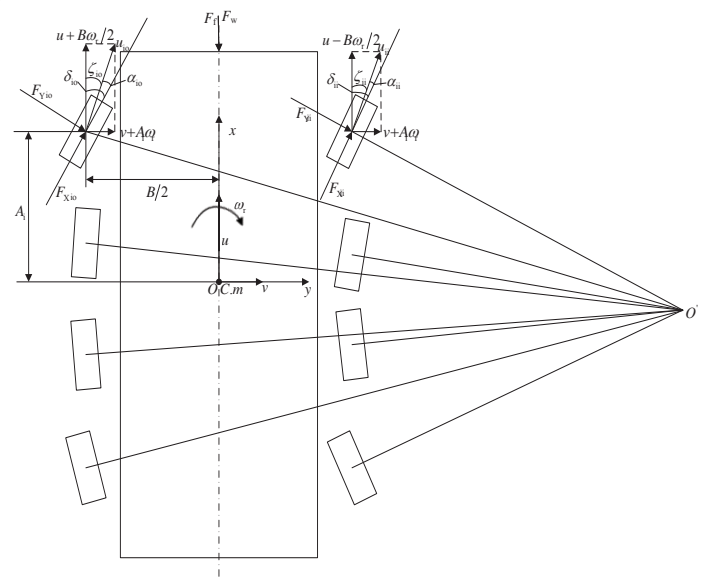

Figure 1. Vehicle dynamics model 
Where $\mathrm{B}$ is the tread of vehicle, $F_{\mathrm{w}}$ is air resistance, $F_{\mathrm{f}}$ is rolling resistance, $F_{\mathrm{Yii}}$ are the lateral reaction force of the ground to the inner wheels, $F_{\text {Yio }}$ are the lateral reaction force of the ground to the outer wheels, $F_{\text {Xii }}$ are the tire longitudinal force of the inner wheels, $F_{\text {Xio }}$ are the tire longitudinal force of the outer wheels, $\delta_{\mathrm{ii}}, \delta_{\mathrm{io}}$ are steering angles of inside and outside wheels respectively, specifies that the wheel steering angle is positive when the car turns right, $\alpha_{\mathrm{ii}}, \alpha_{\mathrm{io}}$ are sideslip angle of inside and outside wheels respectively.

To facilitate the research, the following assumptions are made in this paper in the modeling process of vehicle dynamics:

(1) Ignoring the impact of the car steering system, regard the wheel steering angle as input;

(2) Ignoring the role of the car suspension system, regard that the car only move parallel to the ground, which is the displacement of the car along the $\mathrm{Z}$ axis is 0 ;

(3) The roll angle of the car around the $Y$ axis and the pitch angle around the $\mathrm{X}$ axis are both 0 . The characteristics of each tire are same.

\subsection{Vehicle dynamics model}

The motion equation of the rigid body established by Newtonian mechanics can be described as[7]:

Equation of longitudinal motion:

$$
\begin{aligned}
& \sum F_{\mathrm{Xii}} \cos \delta_{\mathrm{ii}}+\sum F_{\mathrm{Xio}} \cos \delta_{\mathrm{io}}+\frac{|i-2.5|}{i-2.5} \\
& \left(\sum F_{\mathrm{Yii}} \sin \delta_{\mathrm{ii}}+\sum F_{\mathrm{Yio}} \sin \delta_{\mathrm{io}}\right)-F_{\mathrm{w}}-F_{\mathrm{f}}=m\left(\dot{u}-v \omega_{\mathrm{r}}\right)
\end{aligned}
$$

Equation of lateral motion:

$$
\begin{aligned}
& \sum F_{\mathrm{Yii}} \cos \delta_{\mathrm{ii}}+\sum F_{\mathrm{Yio}} \cos \delta_{\mathrm{io}}-\frac{|i-2.5|}{i-2.5} \\
& \left(\sum F_{\mathrm{Xii}} \sin \delta_{\mathrm{ii}}+\sum F_{\mathrm{Xio}} \sin \delta_{\mathrm{io}}\right)=m\left(\dot{v}+u \omega_{\mathrm{r}}\right)
\end{aligned}
$$

Equation of yaw motion:

$$
\begin{aligned}
& \sum A_{\mathrm{i}} F_{\mathrm{Yii}} \cos \delta_{\mathrm{ii}}+\sum A_{\mathrm{i}} F_{\mathrm{Yio}} \cos \delta_{\mathrm{io}}-\frac{|i-2.5|}{i-2.5} \\
& \left(\sum A_{\mathrm{i}} F_{\mathrm{Xii}} \sin \delta_{\mathrm{ii}}+\sum A_{\mathrm{i}} F_{\mathrm{Xio}} \sin \delta_{\mathrm{io}}\right)+ \\
& \frac{B}{2}\left(\sum F_{\mathrm{Xio}} \cos \delta_{\mathrm{io}}-\sum F_{\mathrm{Xii}} \cos \delta_{\mathrm{ii}}+\right. \\
& \left.\frac{|i-2.5|}{i-2.5}\left(\sum F_{\mathrm{Yii}} \sin \delta_{\mathrm{ii}}-\sum F_{\mathrm{Yio}} \sin \delta_{\mathrm{io}}\right)\right)=I_{\mathrm{Z}} \dot{\omega}_{\mathrm{r}}
\end{aligned}
$$

The eight wheels were subjected to force analysis to obtain the wheel motion equation:

Inner wheels:

$$
J_{\omega \mathrm{ii}} \dot{\omega}_{\mathrm{ii}}=T_{\mathrm{dii}}-T_{\mathrm{bii}}-T_{\mathrm{fii}}-F_{\mathrm{Xii}} R_{\mathrm{ii}}
$$

Outer wheels:

$$
J_{\omega i \mathrm{i}} \dot{\omega}_{\mathrm{io}}=T_{\mathrm{dio}}-T_{\text {bio }}-T_{\text {fio }}-F_{\mathrm{Xio}} R_{\mathrm{io}}
$$

Where $J_{\omega \mathrm{ii}}, J_{\omega \text { io }}$ are the moment of inertia of the inner and outer wheels respectively, $\omega_{\mathrm{ii}}, \omega_{\mathrm{io}}$ are the rotation angular velocity of the inner and outer wheels respectively, $T_{\mathrm{di}}, T_{\mathrm{dio}}$ are the driving torque of the inner and outer wheels respectively, $T_{\text {bii }}, T_{\text {bio }}$ are the braking torque of the inner and outer wheels respectively, $T_{\text {fii }}, T_{\text {fio }}$ are the rolling resistance torque of the inner and outer wheels respectively, $R_{\mathrm{ii}}, R_{\mathrm{io}}$ are rotation radius the of the inner and outer wheels respectively.

\subsection{Nonlinear dynamics model}

In this paper, the Pacejka89 magic formula is used to establish the nonlinear vehicle dynamics model[8]. The magic formula tire model is described as:

$$
\begin{gathered}
y(x)=D \sin \{C \arctan [B X-E(B X-\arctan B X)]\} \\
Y(X)=y(x)+S_{\mathrm{v}} \\
X=x+S_{\mathrm{h}}
\end{gathered}
$$

Where $Y$ is longitudinal force, lateral force or aligning torque, $x$ is longitudinal slip rate or sideslip angle, the rest are parameters of magic formula tire model.

The tire vertical load, sideslip angle and longitudinal slip rate are important input parameters in the magic formula tire model. In this model, the effect of aligning torque is not considered.

According to the coordinate system, the sideslip angle of each wheel is:

$$
\begin{gathered}
\alpha_{\mathrm{ii}}=\frac{\beta+\frac{A_{\mathrm{i}}}{u} \omega_{\mathrm{r}}}{1-\frac{B}{2 u} \omega_{\mathrm{r}}}-\delta_{\mathrm{ii}} \\
\alpha_{\mathrm{io}}=\frac{\beta+\frac{A_{\mathrm{i}}}{u} \omega_{\mathrm{r}}}{1+\frac{B}{2 u} \omega_{\mathrm{r}}}-\delta_{\mathrm{io}}
\end{gathered}
$$

The moving speed of each wheel center in the direction of its deflection is:

$$
\begin{aligned}
& u_{\mathrm{ii}}=\left(u-\frac{B}{2} \omega_{\mathrm{r}}\right) \cos \delta_{\mathrm{ii}}-\frac{|i-2.5|}{i-2.5}\left(v+A_{\mathrm{i}} \omega_{\mathrm{r}}\right) \sin \delta_{\mathrm{ii}} \\
& u_{\mathrm{io}}=\left(u+\frac{B}{2} \omega_{\mathrm{r}}\right) \cos \delta_{\mathrm{io}}-\frac{|i-2.5|}{i-2.5}\left(v+A_{\mathrm{i}} \omega_{\mathrm{r}}\right) \sin \delta_{\mathrm{io}}
\end{aligned}
$$

Let $s_{\mathrm{ii}}, s_{\mathrm{io}}$ be the slip rate of the inner and outer wheels respectively, the value is:

$$
\begin{aligned}
& s_{\mathrm{ii}}=\frac{R_{\mathrm{ii}} \omega_{\mathrm{ii}}}{u_{\mathrm{ii}}}-1= \\
& \frac{R_{\mathrm{ii}} \omega_{\mathrm{ii}}}{\left(u-\frac{B}{2} \omega_{\mathrm{r}}\right) \cos \delta_{\mathrm{ii}}-\frac{|i-2.5|}{i-2.5}\left(v+A_{\mathrm{i}} \omega_{\mathrm{r}}\right) \sin \delta_{\mathrm{ii}}}-1 \\
& s_{\mathrm{io}}=\frac{R_{\mathrm{io}} \omega_{\mathrm{io}}}{u_{\mathrm{io}}}-1= \\
& \left(u+\frac{B}{2} \omega_{\mathrm{r}}\right) \cos \delta_{\mathrm{io}}-\frac{|i-2.5|}{i-2.5}\left(v+A_{\mathrm{i}} \omega_{\mathrm{r}}\right) \sin \delta_{\mathrm{io}}
\end{aligned}
$$

The tire vertical load consists of static load and dynamic load, in which the dynamic load, ignoring the effects of lateral winds and road slopes, is caused by the longitudinal acceleration and lateral acceleration of vehicle. This paper uses the solution method in [9].

In this paper, the study of the four-axle vehicle with DFAS system, the steering angle distribution follows the Ackerman principle. 


\section{Control Scheme Design}

In order to improve the steering performance of the four-axle vehicle with independent driving system, in this paper, the steady response and transient response of steering are analyzed and studied. Through establishing the vehicle dynamics simulation model in Matlab/SIMULINK, study the influence of different driving force distribution on the steering performance of the vehicle, and design a control scheme suitable for four-axle vehicle with independent driving system. The parameters of a four-axle vehicle are shown in Table 1.

Table 1. Main Parameters of Vehicle

\begin{tabular}{|c|c|c|}
\hline Symbol & Value & Unit \\
\hline$m$ & 2500 & $\mathrm{~kg}$ \\
\hline$I_{z}$ & 4295 & $\mathrm{~kg} . \mathrm{m}^{2}$ \\
\hline$B$ & 1.4 & $\mathrm{~m}$ \\
\hline$L_{1} / L_{2} / L_{3}$ & $0.75 / 1.2 / 0.75$ & $\mathrm{~m}$ \\
\hline$A_{1} / A_{2} / A_{3} / A_{4}$ & $1.35 / 0.6 /-0.6 /-1.35$ & $\mathrm{~m}$ \\
\hline$h_{\mathrm{g}}$ & 0.5 & $\mathrm{~m}$ \\
\hline$R$ & 0.36 & $\mathrm{~m}$ \\
\hline$J_{\mathrm{w}}$ & 2.5 & $\mathrm{~kg} . \mathrm{m}^{2}$ \\
\hline$C_{\mathrm{d}}$ & 0.8 & \\
\hline$A$ & 1.4 & $\mathrm{~m}^{2}$ \\
\hline$f$ & 0.015 & \\
\hline
\end{tabular}

\subsection{The effect on steady response of different wheel driving force}

Establish the steady steering response model of four-axle vehicle in Matlab / SIMULINK and simulate. The steering angle of the outer wheel of the first axle is $0.008 \mathrm{rad}$, and steering angles of other wheels are set according to Ackerman principle. Set different driving force of inside and outside wheels, front-two-axle and rear-two-axle wheels, different-axle wheels respectively. The simulation results of steady steering characteristics of the vehicle are shown in Figure 2. Where $\mathrm{C}$ and $\mathrm{C}$ 'are positive constants.

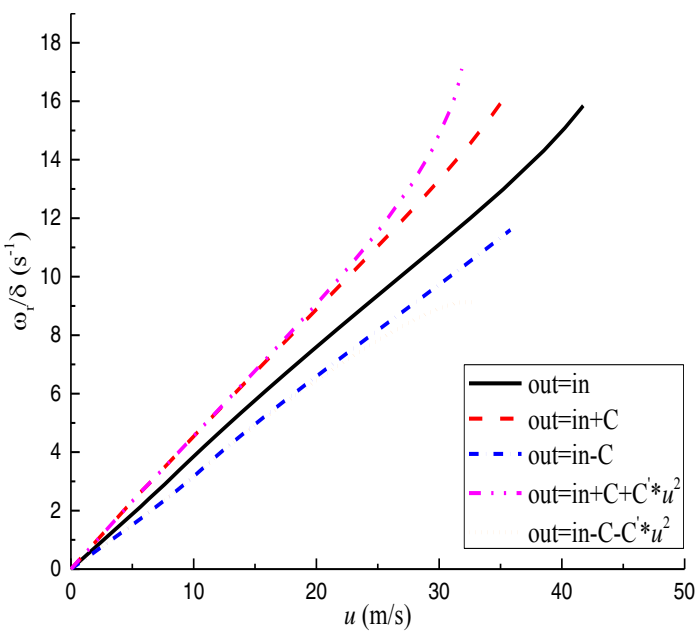

(a) Different driving force of inside and outside wheels

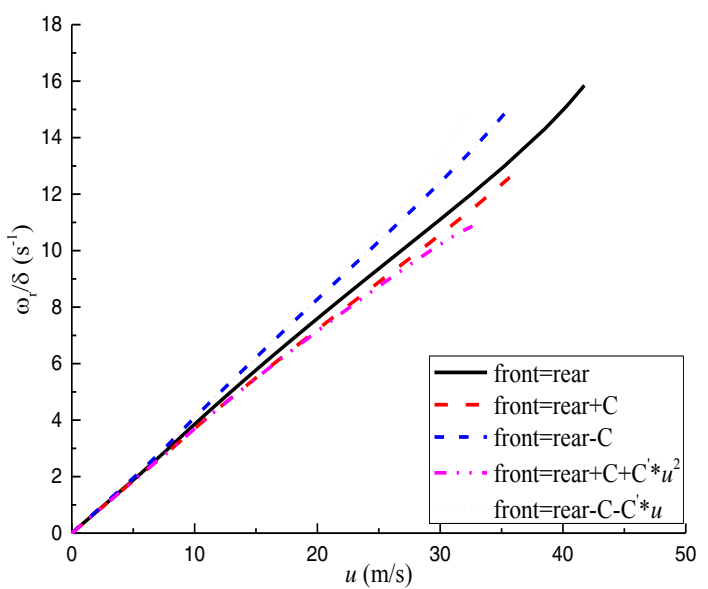

(b) Different driving force of front-two-axle and rear-two-axle wheels

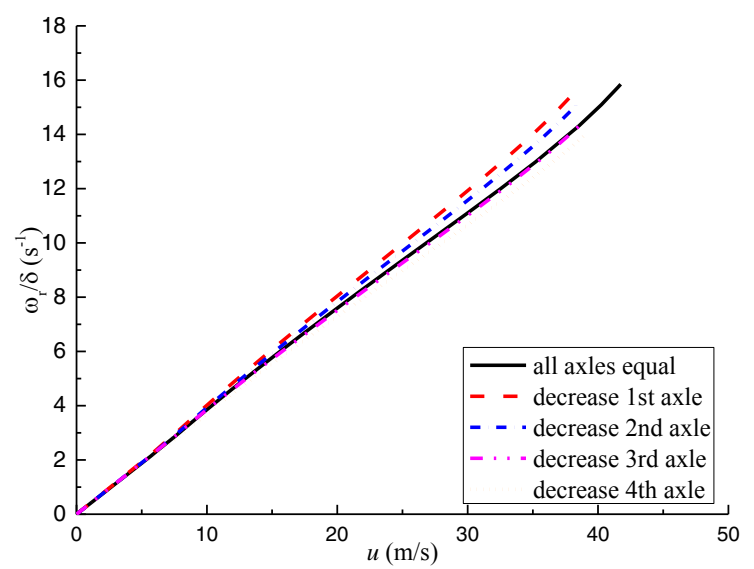

(c) Different driving force of different-axle wheels

Figure. 2 The effect on steady response of different wheel driving force

As seen as in the Figure 2, the steering characteristic of the four-axle vehicle is neutral steering. The Figure 2. (a) (b) indicates that when the driving force of the outer wheel is larger than the driving force of the inner wheel, the yaw rate gain of the vehicle increases, otherwise the yaw rate gain decreases; when the driving force of the front-two-axle wheels is greater than the driving force of the rear-two-axle wheels, the yaw rate gain of the vehicle decreases; otherwise the yaw rate gain increases. With the increase of speed, increase the difference between the driving forces of two parts wheels, the steering characteristics of the vehicle will change, become oversteering or understeering, and it can be seen that the difference between inside and outside wheels can change the steering characteristics of the vehicle more effectively. The Figure 2.(c) indicates that reducing the wheel driving force of first or second axle will cause the yaw rate gain increase, reducing the wheel driving force of forth axle will cause the yaw rate gain decrease, changing the wheel driving force of the third axle has little effect on the yaw rate gain; wherein changing the wheel driving force of the first axle has the greatest effect on the yaw rate gain.

So when the steering characteristic of vehicles change from neutral steering to oversteering or severe understeering due to the changes of vehicle parameters in 
the actual use, the steering characteristics can be improved by changing the driving force of the different wheels. As the difference of driving force between inside and outside wheels can greatly change the steering characteristics, it is possible to improve the steady response by setting different driving force between inside and outside wheel according to the actual steering characteristics of the vehicle when steering.

\subsection{The effect on transient response of different wheel driving force}

Establish the transient steering response model of four-axle vehicle in Matlab / SIMULINK and simulate under the steering wheel angle step input. The step value of the steering angle of the outer wheel of the first axle is $0.02 \mathrm{rad}$, and steering angles of other wheels are set according to Ackerman principle. The initial speed of vehicle is $72 \mathrm{~km} / \mathrm{h}$. Will be 8 wheels of the four-axle vehicle are divided into 4 groups, namely, outside of front-two-axle(OF), inside of front-two-axle(IF), outside of rear-two-axle(OR), inside of rear-two-axle(IR). Reduce $28 \%$ of the driving force, simulate and analyze the change of sideslip angle and yaw rate, the results are shown in Figure 3.

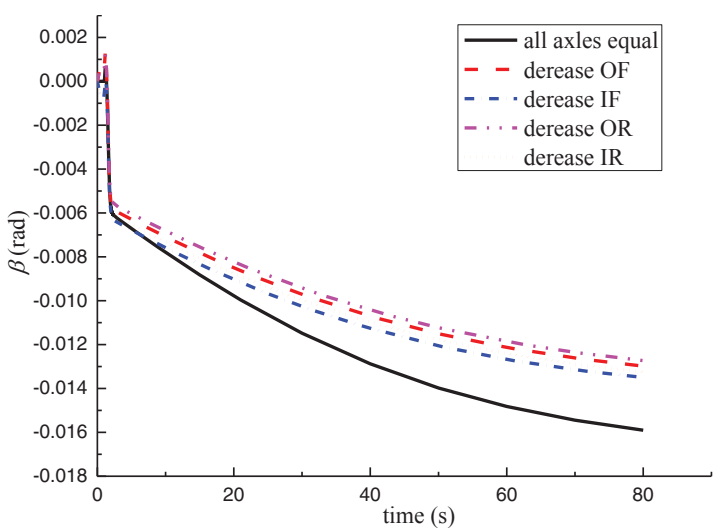

(a)Changes of sideslip angle under different driving force

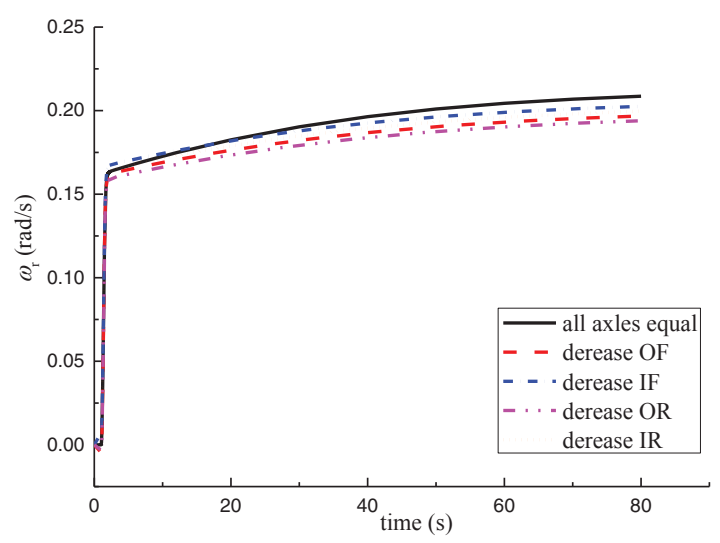

(b) Changes of yaw rate under different driving force

Figure 3. The effect on transient response of different wheel driving force

As seen as in the Figure 3, reduce the driving force of each group can make the value of sideslip angle and yaw rate decrease. When the steering angle is positive, reducing the driving force of outside wheels of rear-two-axle is most effective for improving the transient response, and the value decreases by $20 \%$. If the steering angle is negative, it should reduce the driving force of outside wheels of rear-two-axle. (Corresponding outside wheel is opposite when the steering angle is positive or negative)

Establish the control strategy of transient response of the four-axle vehicle according to the above analysis. Select wheels to control driving force according to the positive and negative of steering angle. In this paper, we use the zero sideslip angle control strategy[10]. When steering, the corresponding wheels are selected by the driving force distribution module, and the driving force is controlled by the PID control algorithm to prevent the vehicle from entering the unsteady state. The structure of the control system is shown in Figure 4.

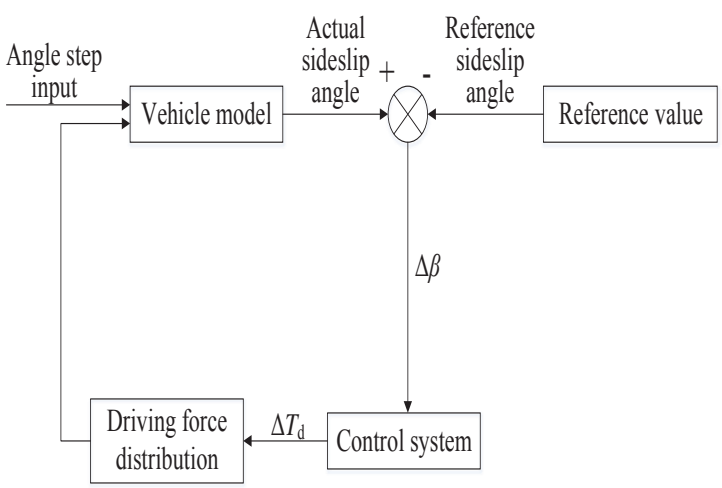

Figure 4. Structure of the control system of transient response

\section{Simulation And Analysis Of Zero Sideslip Angle Control}

Establish the transient response control model based on the control strategy described in 3.2 to optimize sideslip angle by feedback control.

\subsection{Simulation under angle step input}

The step value of the steering angle of the outer wheel of the first axle is $0.02 \mathrm{rad}$, and steering angles of other wheels are set according to Ackerman principle. The initial speed of vehicle is $72 \mathrm{~km} / \mathrm{h}$. The simulation results are shown in Figure 5.

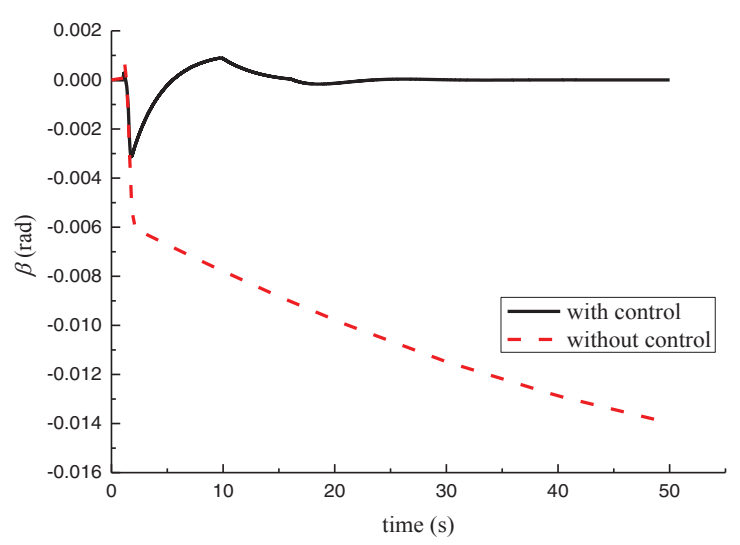

(a) Contrast of sideslip angle under angle step input 


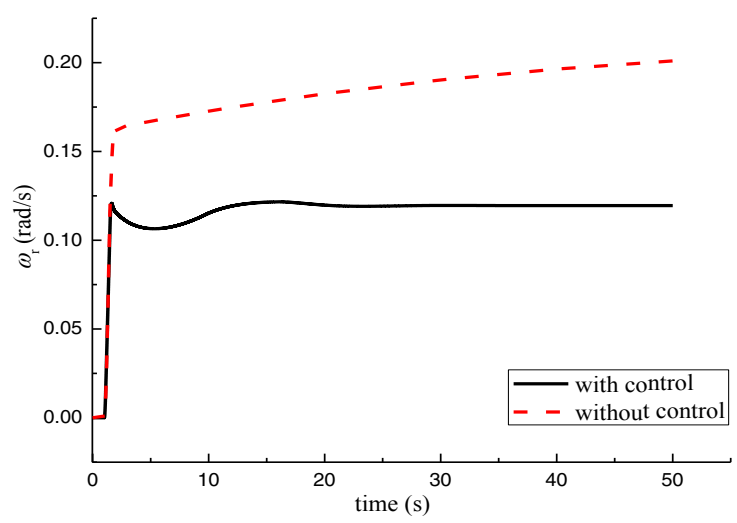

(b) Contrast of yaw rate under angle step input

Figure 5. Contrast of transient response under angle step input

As seen as in the Figure 5. under the control of PID based on the control strategy of zero sideslip angle, the sideslip angle can be quickly stabilized at around 0 by controlling the driving force of the outside wheels of rear-two-axle, but in the case of no control, the value of sideslip angle is larger and there is a trend of instability. And the yaw rate of the vehicle also greatly decreases relative to the situation of no control.

\subsection{Simulation under sine input}

The amplitude of sine input of the steering angle of the outer wheel of the first axle is $0.02 \mathrm{rad}$, the frequency is $1 / \pi \mathrm{Hz}$, and steering angles of other wheels are set according to Ackerman principle. The initial speed of vehicle is $72 \mathrm{~km} / \mathrm{h}$. The simulation results are shown in Figure 6.

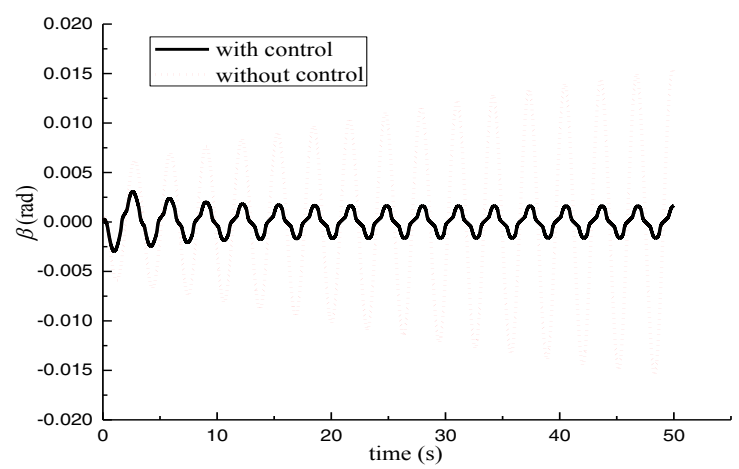

(a) Contrast of sideslip angle under sine input

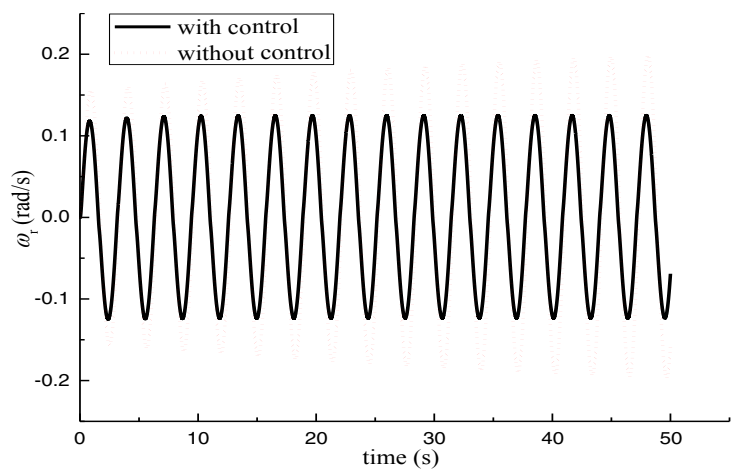

(b) Contrast of yaw rate under sine input

Figure 6. Contrast of transient response under sine input
As seen as in the Figure 6. relativing to the situation of no control, the PID control based on the zero sideslip angle can significantly reduce the sideslip angle of the vehicle under sine input, and the yaw rate also greatly decreases.

According to the simulation and analysis, for four-axle vehicle with independent driving system, controlling the driving force of outside wheels of rear-two-axle by using the PID control based on control strategy of zero sideslip angle can improve the transient response characteristics well to make vehicle maintain a steady state during steering.

\section{Conclusion}

(1) In this paper, the influence of different driving force distribution scheme on the steering performance of the vehicle is analyzed by establishing the nonlinear multi-axis vehicle dynamics model. According to the above method, the control strategy of improving the steering response and transient response of the vehicle can be obtained.

(2) For steady steering characteristics, set different driving force between inside and outside wheels or front-two-axle and rear-two-axle wheels of the vehicle can both change its characteristics, wherein, the difference of driving force between inside and outside wheels is more effective. For transient steering characteristics, reducing the driving force of outside wheels of rear-two-axle is most effective for reducing the sideslip angle, and the value decreases by $20 \%$ when the driving force is reduced by $28 \%$.

(3) Using PID control algorithm based on control strategy of zero sideslip angle to control the driving force of outside wheels of rear-two-axle when steering, under angle step input the sideslip angle can be quickly stabilized at around 0 and the yaw rate also greatly decreases, and under sine input the sideslip angle significantly reduces and the yaw rate also greatly decreases, which prove that the control method is valid.

\section{References}

1. Jin Shu, Sizhong Chen, Lin Yang. Design of multi-wheel independent steering control system for multi-axle vehicle [J]. Traffic and Computer, (06): 57-59, (2003).

2. A. Hakima, S. Ameli, Designing a fuzzy logic controller to adjust the angle of tires in four wheel steering vehicles[C]//Control Automation Robotics \& Vision (ICARCV), 2010 11th International Conference on. IEEE, 2010: 2208-2213.

3. N. Hamzah, M.K. Aripin, Y.M. Sam, et al. Yaw stability improvement for four-wheel active steering vehicle using sliding mode control[C]//Signal Processing and its Applications (CSPA), 2012 IEEE 8th International Colloquium on. IEEE, 127-132, (2012).

4. D.E. Williams, Generalised multi-axle vehicle handling $[\mathrm{J}]$. Vehicle System Dynamics, 50(1): 149-166, (2012). 
5. B. Tabbache, A. Kheloui, M.E.H. Benbouzid, An adaptive electric differential for electric vehicles motion stabilization[J]. IEEE Transactions on Vehicular Technology, 60(1): 104-110, (2011).

6. Lei Qiu. Simulation and Research on Vehicle Electronic Stability Program Control System [D]: Chongqing University, (2013).

7. Zhisheng Yu. The theory of automobile [M]. Beijing: Mechanical Industry Press, (2009).
8. Feng Yang, Parameters Identification for common steady-state tyre models based on excel solver [D]: Jilin University, (2011).

9. Xiao Jiang. Research on AWS System Dynamics of Multi-axle Research on AWS System Dynamics of Multi-axle Vehicle [D]: Beijing Institute of Technology,(2017).

10. Yunchao Wang, Research on steering performance of multi-axle steering vehicle[D]: Jilin University, (2007). 